\title{
Molecular approach for identification of mosquito species (Diptera: Culicidae) in Province of Alessandria, Piedmont, Italy
}

\author{
AsGHAR TALBALAGHI ${ }^{1,2}$ and ElENA SHAIKEVICH ${ }^{3}$
}

\author{
${ }^{1}$ Mosquito Control District of Alessandria \\ ${ }^{2}$ European Mosquito Control Association, Italy; e-mail: zanzare@zanzare.eu \\ ${ }^{3}$ Group of Insect Genetics, Department of Comparative Genetics of Animals, N.I. Vavilov Institute of General Genetics, \\ Russian Academy of Sciences, Gubkin Str. 3, Moscow 119991, Russia; e-mail: elenashaikevich@mail.ru
}

Key words. Mosquitoes, Culicidae, Anopheles maculipennis, Ochlerotatus caspius, Culex pipiens, PCR-RFLP, ITS2, COI

\begin{abstract}
The aim of the present work was to identify cryptic species in the Anopheles maculipennis and Culex pipiens complexes and to study the genetic structure of the dominant mosquito species Ochlerotatus caspius (Diptera: Culicidae) in the Province of Alessandria close to the vast area untreated rice fields in Piedmont, NW Italy. With the help of PCR-RFLP analysis, four members of the Anopheles maculipennis complex were identified: A. messeae, A. maculipennis, A. sacharovi and A. atroparvus. Only C. pipiens f. molestus was identified in 11 habitats studied in Piedmont. Partial sequences of the cytochrome c oxidase subunit 1 (COI) mitochondrial gene and the second internal transcribed spacer (ITS2) of nuclear ribosomal RNA genes for Italian $O$. caspius are reported here for the first time. The results indicate that this species diverged from Iranian representatives of this species about one million years ago. The great diversity of mosquito species in Piedmont considerably increases the risk of vector-borne dise ases.
\end{abstract}

\section{INTRODUCTION}

Exact identification of mosquitoes is essential for controlling the species that are vectors of human and animal diseases. It is particularly difficult to identify representatives of species complexes, such as Anopheles maculipennis and Culex pipiens (Diptera: Culicidae). The morphology of larvae and adults of species within these complexes are similar or identical. However, they do show considerable differences in ecological and physiological features, including food preferences. Their epidemiological significance is also different.

Importantly, the causative agents of many diseases are transferred between hosts by certain species of bloodsucking Culicidae (e.g. Turell et al., 2001; Becker et al., 2003; McAbee et al., 2008). In a recent study, the following dangerous viruses were detected in pooled mosquito samples from N Italy: West Nile virus in C. pipiens, two orthobunya viruses and Tahyna virus in Ochlerotatus caspius and Batai virus in A. maculipennis (Cazolari et al., 2010). Since different species within these complexes can sustain arboviral outbreaks (Talbalaghi et al., 2010), specific diagnosis of the vectors is essential for developing control strategies.

Unfortunately, morphological features are often insufficient for identifying species of bloodsucking mosquitoes as some are very variable and consequently unreliable [for example, siphonal index of $C$. pipiens larvae (Fedorova \& Shaikevich, 2007)], while many diagnostic features (especially paleolae and chaetae) are not present on collected material. This problem can be solved by using molecular-genetic analysis and developing DNA markers for specifically identifying species and subspecies of these insects.
One of the basic molecular-genetic markers used to study species composition of mosquitoes is the second internal transcribed spacer (ITS2) of nuclear ribosomal ribonucleic acid (rRNA) genes. rRNA genes of mosquitoes are represented in the genome as a set of tandem repeats. Each transcriptional unit consists of the genes encoding three ribosomal RNAs (18S, 5.8S, and 28S) separated by internal transcribed spacers ITS1 and ITS2. The coding $28 \mathrm{~S}$ gene sequence is followed by an external transcribed spacer. Transcriptional units are separated by un-transcribed spacers. The rRNA genes are conserved, whereas internal transcribed spacers are variable and useful for comparing species. It is known that the structure of ITS2 varies among different mosquito species (Porter \& Collins, 1991), the length being from $421 \mathrm{bp}$ in A. maculipennis to $442 \mathrm{bp}$ in $A$. sacharovi, however $A$. messeae, A. melanoon, A. atroparvus, and A. labranchia have a fragment of similar length (Marinucci et al., 1999). Recently, a complex of PCR-RFLP methods was developed to identify some cryptic species in the Anopheles maculipennis complex (Nicolescu et al., 2004; Ejov et al., 2008).

Another approach is to analyze the 5' end of the cytochrome c oxidase subunit 1 mitochondrial gene (COI). This region, known as the DNA barcode (Barcode of Life Initiative, 2003), was used previously to study the Iranian O. caspius (Azari-Hamidian et al., 2009). For $O$. caspius in Italy, microsatellite and allozyme polymorphism and mitochondrial COII gene structure are reported (Porretta et al., 2007). Although the nucleotide structure of the ITS2 area of $C$. pipiens is variable it cannot be used to distinguish between $C$. pipiens and $C$. pipiens f. molestus, however, a method based on the analysis of the 5 'end 
TABLE 1. Sampling locations, population number (sample code) and date of collection.

\begin{tabular}{|c|c|c|c|c|c|}
\hline Municipality & Sample & Sample code & $\begin{array}{c}\text { Date of sample } \\
\text { or capture }\end{array}$ & $\begin{array}{c}\text { Number of specimens } \\
\text { identified }\end{array}$ & Storing conditions \\
\hline & AdULT & & & & \\
\hline Alessandria & O. caspius & 1 & 08.ix.2009 & 1 & Ethanol \\
\hline Alessandria & O. caspius & 2 & 25.viii.2009 & 1 & Ethanol \\
\hline Valle S.Bartolomeo & O. caspius & 3 & 01.ix.2009 & 1 & Ethanol \\
\hline Alluvioni Cambiò & C. pipiens & 5 & 26.viii.2009 & 3 & Ethanol \\
\hline Alluvioni Cambiò & O. caspius & 7 & 02.ix.2009 & 1 & Ethanol \\
\hline Bosco Marengo & O. caspius & 10 & 01.vii.2009 & 1 & Dry \\
\hline Castellazzo Bormida & C. pipiens & 13 & 17.viii.2009 & 2 & Dry \\
\hline Castellazzo Bormida & O. caspius & 15 & 17.viii.2009 & 1 & Dry \\
\hline Frugarolo & C. pipiens & 18 & 17.vi.2009 & 2 & Dry \\
\hline Ovada & C.pipiens & 24 & 29.ix.2009 & 4 & Dry \\
\hline Ovada & Anopheles spp. & 25 & 26.viii.2009 & 1 & Dry \\
\hline Rivarone & Anopheles spp. & 33 & 10.viii.2009 & 1 & Dry \\
\hline Alessandria & C. pipiens & 35 & 01.ix.2009 & 2 & Dry \\
\hline \multirow[t]{2}{*}{ Alessandria } & Anopheles spp. & 36 & 08.ix.2009 & 2 & Dry \\
\hline & LARVAE & & & & \\
\hline Alluvioni Cambiò & Anopheles spp. & 67 & 26.viii.2009 & 2 & Ethanol \\
\hline Alessandria & C. pipiens & 69 & 28.viii.2009 & 1 & Ethanol \\
\hline Gamalero & C. pipiens & 70 & 24.viii.2009 & 5 & Ethanol \\
\hline Oviglio & C. pipiens & 71 & 25.viii.2009 & 8 & Ethanol \\
\hline Tortona & C. pipiens & 73 & 26.viii.2009 & 5 & Ethanol \\
\hline Novi Ligure & C.pipiens & 74 & 24.viii.2009 & 5 & Ethanol \\
\hline Tassarolo & C. pipiens & 75 & 24.viii.2009 & 9 & Ethanol \\
\hline
\end{tabular}

of the mitochondrial $C O I$ gene can be successfully used to identify mosquitoes of the $C$. pipiens comlex (Shaikevich, 2007).

In this study, simple PCR-based assays (amplification of the ITS2 within nuclear rRNA genes of the $A$. maculipennis complex and amplification of the $C O I$ gene within mtDNA of $C$. pipiens complex followed by endonuclease digestion) were used for the molecular identification of cryptic species.

\section{MATERIAL AND METHODS}

\section{Study area and sampling sites}

The adults and larvae of the mosquitoes analyzed were collected in the Province of Alessandria close to the vast area of untreated rice fields in Piedmont, NW Italy. The Province of Alessandria is $10 \mathrm{~km}$ from the biggest mosquito breeding site in Europe, approximately 220,000 ha of rice fields, which produce $50 \%$ of the rice grown in Europe. These rice fields are unique in being a major breeding area for $O$. caspius (Pallas, 1771) from April to July and later a breeding area for Culex spp. and the $A$. maculipennis group.

Samples of insects were collected weekly by a monitoring network of $\mathrm{CO}_{2}$ traps (see Table 1). The genera and species complexes were identified morphologically.

\section{DNA isolation and analysis}

Mosquito DNA was extracted using DIAtom ${ }^{\mathrm{TM}}$ DNA Prep kit (Isogen, Moscow, Russia). DNA samples were obtained from individual larvae and adults, either dry or preserved in $96 \%$ ethanol. Prior to DNA isolation from the ethanol-preserved material, ethanol was evaporated off by heating at $65^{\circ} \mathrm{C}$ for 30-40 min.

\section{PCR-RFLP assay}

The mtDNA gene COI was amplified using primers LCO and HCO (Folmer et al., 1994) for studying O. caspius and Culex-
COIF and Culex COIR (Shaikevich, 2007) for studying C. pipiens. The ribosomal ITS2 region was amplified using primers 5.8S and 28S (Porter \& Collins, 1991) at research both O. caspius and Anopheles spp.

PCR amplification reactions were run in a final volume of 25 $\mu 1$ with PCR buffer (Isogen), $20 \mu \mathrm{M}$ of each dNTP, $2.5 \mathrm{mM}$ $\mathrm{MgCl}_{2}$, one unit of Taq DNA polymerase, $0.2 \mu \mathrm{M}$ of each primer and $0.1 \mu \mathrm{g}$ of the isolated DNA. Thermocycler conditions were as recommended for each primer pair.

For the Anopheles maculipennis complex, the improved PCRRFLP method was used (Ejov et al., 2008). The PCR-RFLP was run using $C f o \mathrm{I}$ (Promega, Madison, WI, USA) and BctACI (Sibenzyme, Moscow, Russia) endonucleases. Restriction volumes were $20 \mu \mathrm{l}$. The digestion mixtures consisted of (i) $3 \mu 1$ of the ITS2 PCR-product, $0.5 \mu \mathrm{l}(5 \mathrm{U})$ of $C f o \mathrm{I}, 2 \mu \mathrm{l}$ of the manufacturer's incubation buffer, $0.2 \mu$ BSA (Promega) and $14.3 \mu \mathrm{l}$ $\mathrm{ddH}_{2} \mathrm{O}$, and (ii) $3 \mu \mathrm{l}$ of the ITS2 PCR-product, $0.5 \mu \mathrm{l}(5 \mathrm{U})$ of $B c t A C \mathrm{I}, 2 \mu \mathrm{l}$ of the manufacturers incubation buffer and $14.5 \mu \mathrm{l}$ $\mathrm{ddH}_{2} \mathrm{O}$ (BSA is included in all Sibenzyme's incubation buffers). Incubation time was not less then $2 \mathrm{~h}$ at $37^{\circ} \mathrm{C}$.

For the precise identification of $C$. pipiens mosquitoes using the PCR-RFLP assay amplicons were digested with HaeIII (Promega) restriction endonuclease. Restriction enzyme digestions were performed in $20 \mu 1$ volume. Digest master mix consisted of $5 \mu 1$ of the COI PCR product, $0.5 \mu \mathrm{l}(5 \mathrm{U})$ of HaeIII, 2 $\mu 1$ buffer C (Promega), $0.2 \mu 1$ BSA (Promega) and $12.3 \mu 1$ $\mathrm{ddH}_{2} \mathrm{O}$. The HaeIII restriction reaction was incubated for $1 \mathrm{~h}$ at $37^{\circ} \mathrm{C}$. The digested products were visualized on a $2 \%$ agarose gel.

\section{Sequence analysis}

PCR products were identified by electrophoresis, using a $1 \%$ agarose gel (Sigma, St. Louis, MO, USA). Amplified DNA fragments were isolated from the gel using JetQuiCk Gel Extraction Spin Kit (Genomed, Loehne, Germany) and then directly sequenced on an ABI PRISM 310 using the ABI PRISM BigDye Terminator Cycle Sequencing kit (Applied Bio- 


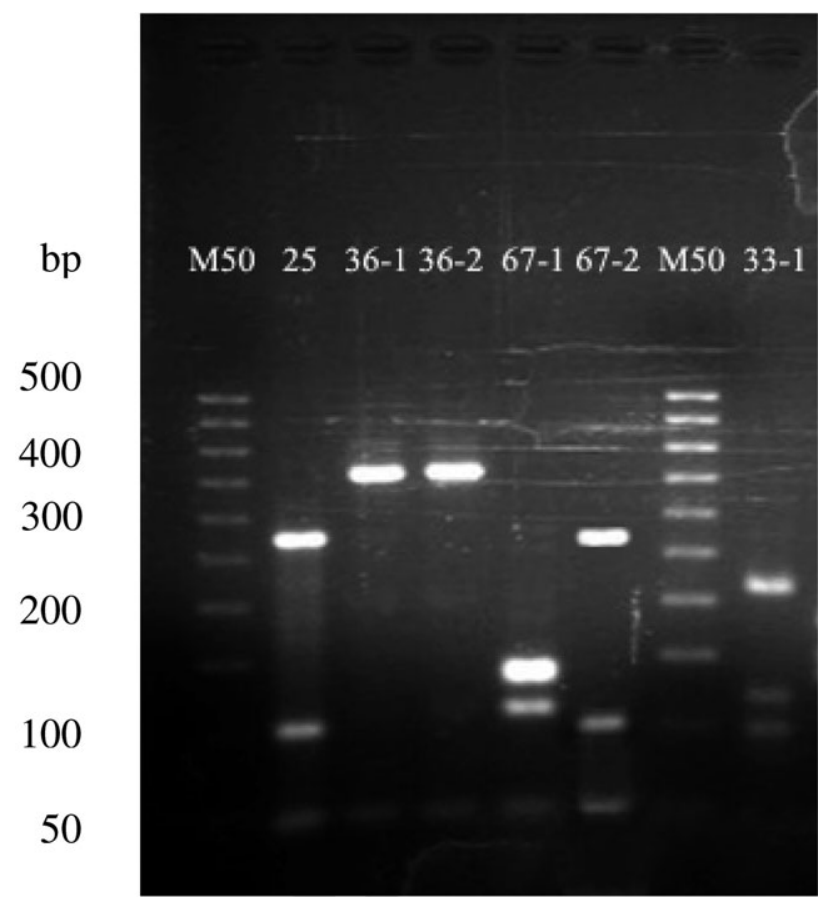

Fig. 1. Fragments resulting from restriction with $C f o$ I of ITS2 amplificates of $A$. maculipennis complex mosquitoes from Piedmont; M50 - 50 bp ladder (Isogen, Moscow, Russia): 500, 450, $400,350,300,250,200,150,100,50 \mathrm{bp}$. The sample codes above lanes correspond to those in Table 1 .

systems, Foster City, CA, USA) according to the instructions of the manufacturer. The obtained sequences of $O$. caspius DNA are available in GenBank under accession numbers HM140413-HM140418 for COI and HM140419-HM140424 for ITS2. The DNA sequences were aligned using ClustalW and analyzed using MEGA version 4 (Tamura et al., 2007).

\section{RESULTS AND DISCUSSION}

\section{Anopheles spp.}

The PCR with primers $5.8 \mathrm{~S}$ and $28 \mathrm{~S}$ produced amplicons with lengths typical for mosquitoes of the complex A. maculipennis (420-440 bp). An improved PCR-RFLP method was used to identify species of the A. maculipennis complex (Ejov et al., 2008). Identification was based on species-specific restriction sites in the ITS2 locus. The recognition site for $C f o \mathrm{I}$ is the sequence GCGC. After digestion with $C f o I$, variable fragments were obtained (Fig. 1). Two fragments (56 and 42 bp) are characteristic for all members of the A. maculipennis complex. Because of their low molecular weight these fragments merged into one another on agarose gels (about $50 \mathrm{bp})$.

For individuals from population 36, 389-bp and 50-bp fragments, common for $A$. atroparvus, were obtained. DNA of the mosquito from population 33 was cut into fragments of $207,111,78$, and $50 \mathrm{bp}$, corresponding to $A$. sacharovi. $50 \mathrm{bp}$ is almost not visible in lane 33-1 on Fig. 1 , but other visible fragments are specific only for $A$. sacharovi (Nicolescu et al., 2004). For the individuals from populations 25 and 67 (sample 67-2) restriction fragments of 272,102 , and $50 \mathrm{bp}$ were obtained. These

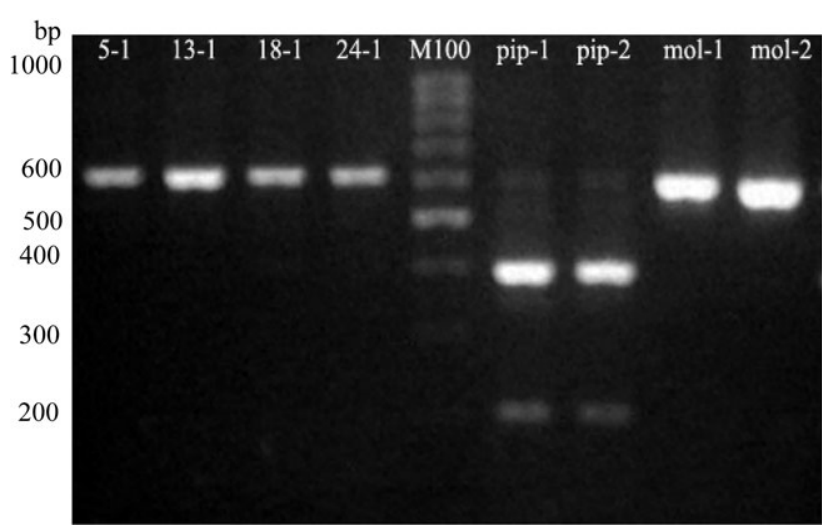

Fig. 2. Fragments resulting from restriction with HaeIII of $603 \mathrm{bp}$ amplificates of DNA of COI gene of C. pipiens from Piedmont: 5-1, 13-1, 18-1, 24-1 (the sample codes correspond to the numbers in Table 1); of anautogenous mosquitoes from open rural habitats in the region of Moscow (pip-1) and Krasnodar (pip-2); of autogenous mosquitoes from basement habitats in Moscow (mol-1) and Krasnodar (mol-2); M100 - 100 bp ladder (Isogen) 1000, 900, 800, 700, 600, 500 (bright), 400, 300, 200, $100 \mathrm{bp}$.

fragments correspond to A. maculipennis. DNA from other individual from population 67 (sample 67-1) was cut into fragments of $141,135,111$ and $50 \mathrm{bp}$, as in both A. messeae and A. melanoon. For exact identification of the latter one an additional restriction reaction with BstACI was run, which indicated fragments of 292 and $150 \mathrm{bp}$, common for ITS2 of $A$. messeae (not shown). (There is no site for BctACI in the ITS2 of the DNA of $A$. melanoon).

The analysis of Anopheles spp. from various biotopes using PCR-RFLP revealed four members of the $A$. maculipennis complex: A. messeae, A. maculipennis, A. sacharovi, and $A$. atroparvus.

Five species of the $A$. maculipennis complex are common in Europe: A. maculipennis, A. messeae, A. melanoon, $A$. sacharovi, and $A$. atroparvus. All are zooand anthropophilic and attack humans and animals both indoors and outdoors. After feeding on blood, A. maculipennis, A. sacharovi, $A$. messea, and $A$. atroparvus rest indoors (are endophilic), while $A$. melanoon rests outdoors (is exophilic). $A$. messeae hibernates, while $A$. maculipennis, $A$. melanoon, $A$. sacharovi, and $A$. atroparvus can suck blood all year round, but do not lay eggs in winter. Therefore, a correct identification of the vectors is essential for the development of control strategies. Since the mtDNA of $A$. maculipennis mosquitoes is more polymorphic than the ITS regions of the rRNA transcriptional units, using the ITS2 sequences for the PCRRFLP analysis for identifying the species within this complex is likely to prove more accurate. It has been possible to identify species using these methods and these markers are very promising for use in future studies.

\section{Culex pipiens}

The $C$. pipiens complex in Europe is represented by Culex pipiens (Linnaeus) and C. pipiens f. molestus (Forskal). Although very similar in morphology these two 


$\begin{array}{lccc} & \boldsymbol{C O I} & & \text { ITS2 } \\ {[} & 123355] & & {[111]} \\ {[} & 3690146] & 1] & {[7555]} \\ {[} & 7579231] & 3] & {[2127]} \\ \text { Och1 } & \text { GGAAATA } & \text { V } & \text { A--A } \\ \text { Och2 } & \ldots \ldots & . & \text { GACG } \\ \text { Och3 } & \ldots \ldots & . & \text { GACG } \\ \text { Och7 } & . \text { A.... } & . & \text { GACG } \\ \text { Och15 } & \text { A. ...AG } & \text { I } & \text { GACG } \\ \text { Och10 } & \text { A.GGGAG } & \text { I } & \text { GACG }\end{array}$

Fig. 3. Variable nucleotide and amino acid sites of the $563 \mathrm{bp}$ 5 'region of COI (Barcode fragment) and variable nucleotide sites of the ITS2 fragment of $O$. caspius from Piedmont. The sample codes correspond to those in Table 1. Vertical numbers in square bracklets indicate positions of variable sites. $\mathrm{V}$ valine; $\mathrm{I}$ - isoleucine.

forms are quite different in their physiology and behaviour. C. pipiens is rather ornithophilic while C. pipiens $\mathrm{f}$. molestus is mostly anthropophilic. C. pipiens is anautogenous (unable to lay a batch of eggs until it has had blood meal) and eurygamous (unable to mate in confined spaces). In contrast, the molestus form is autogenous (can produce a first batch of eggs prior to feeding on a blood meal) and eugamous (mates in confined spaces). $C$. pipiens can hibernate, but not C. pipiens f. molestus. Although both forms are vectors there is no data on their relative abilities as vectors of disease.

Earlier, the DNA polymorphism in a 603-bp fragment of the 5'end of the mitochondrial COI gene of two forms of $C$. pipiens from Russia was used to develop PCRRFLP assays using HaeIII restriction endonuclease to distinguish between anautogenous (pipiens) and autogenous (molestus) forms (Shaikevich, 2007). After restriction of amplificates of DNA of COI gene using endonuclease HaeIII two fragments (206 and $397 \mathrm{bp}$ ) were recorded in anautogenous C. pipiens, whereas the 603 amplicon from autogenous $C$. pipiens remained unchanged (Fig. 2). This method was used in the analysis of mosquitoes from Piedmont. Some examples are presented in Fig. 2. After amplification and digestion with HaeIII only the uncut 603-bp fragment was obtained for all the specimens of $C$. pipiens studied. Altogether 48 individuals of the molestus form were identified in Piedmont using restrictase HaeIII. Almost all the C. pipiens studied were collected from cans, water containers and sewage water in an urban area. Homogeneous populations of the anthropophilic form molestus were recorded in 11 populations (see Table $1)$.

Mainly anthropophilic populations of C. pipiens are recorded in Egypt (Gad et al., 1999). In regions of southern Russia in summer, mosquitoes of the molestus form may temporarily establish homogeneous populations or coexist with the anautogenous form of pipiens in above-ground water bodies (barrels) (Vinogradova et al.,

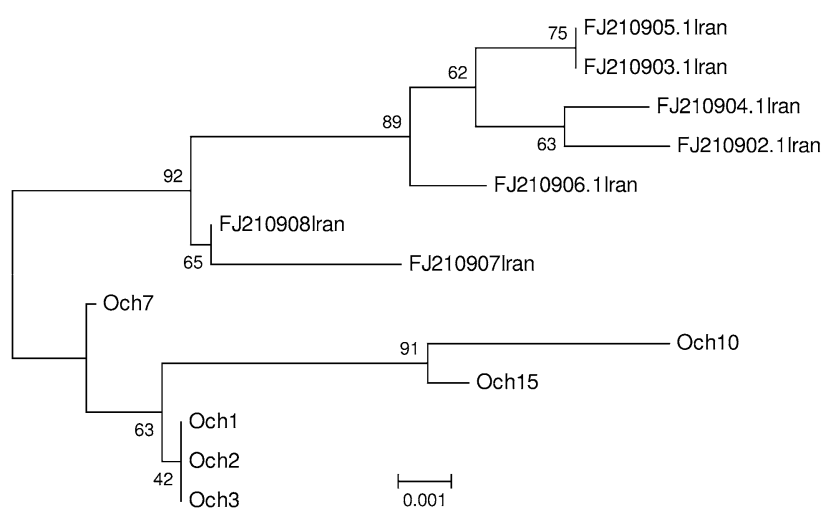

Fig. 4. Dendrogram based on 563 bp COI gene mtDNA sequence data of the relationship of the haplotypes within $O$. caspius. Och1, Och2, Och3, Och7, Och10, and Och15 - O. caspius from Piedmont; the sample numbers correspond to those in Table 1. The tree was constructed using neighbour-joining method with Kimura 2-parameter distances. Numbers are bootstrap percentages (1000 replicates).

2007). Heterogeneous populations are also recorded in Germany, where some populations in water barrels, buckets, and garden ponds consist of up to $20 \%$ of the autogenous form (Becker et al., 1999).

These results confirm that molestus mosquitoes can survive if the temperature conditions are favourable in open habitats, although in northern zones these mosquitoes occur mostly underground and biotopically separated from the form pipiens.

\section{Ochlerotatus caspius}

The 563-bp sequences of the mitochondrial gene COI (The Barcode fragments) of O. caspius were obtained for specimens from six populations 1, 2, 3, 710 and 15 (Table 1). Four unique haplotypes were identified. The individuals studied varied by less than $1 \%$. The mosquitoes from populations 1,2 and 3 were identical in this 563-bp DNA fragment. DNA from a mosquito of population 7 differed by only one nucleotide. The highest polymorphism was shown by a mosquito from population 10 : six nucleotide substitutions. Most substitutions were at the third codon positions and did not affect the amino acid sequence. Only the transition $\mathrm{G} \rightarrow \mathrm{A}$ at position 37 at the first codon position results in the amino acid substitution valine-isoleucine $(\mathrm{Val} \rightarrow \mathrm{Ile})$; this substitution was detected in two of the mosquitoes studied from populations 10 and 15 (Fig. 3).

GenBank search revealed that the $C O I$ sequences of $O$. caspius from Piedmont share a $98 \%$ similarity with specimens from Iran (Azari-Hamidian et al., 2009). The neighbour-joining dendrogram shows two clusters: the first is formed by Italian and the second - Iranian $O$. caspius (Fig. 4).

In addition, sequences of the variable ITS2 region were analyzed in the ribosomal RNA of $O$. caspius. Samples from the same populations: 1, 2, 3, 7, 10, and 15 (Table 1) were studied. The size of the obtained PCR fragments of the ITS2 region of $O$. caspius was about $370 \mathrm{bp}$ (not shown). Primers were selected so that the ITS2 sequences 
were flanked with a 88-bp fragment of the 5.8S and 45-bp fragment of the $28 \mathrm{~S}$ rRNA genes. Therefore, the size of the actual ITS2 of $O$. caspius is about $254 \mathrm{bp}$.

The ITS2 of the five individuals investigated was almost identical. Only one mosquito differed from the others by two nucleotide substitutions and one deletion. Four variable sites were detected in six sequences (Fig. 3). Pair-wise distances between samples from different populations varied from 0 to $1.1 \%$. In comparison with all ITS2 sequences of $O$. caspius from Spain and Tunis available in GenBank, the overall average pair-wise distance is below $0.2 \%$.

Unfortunately, only the mtDNA of Iranian mosquitoes was studied and only ITS2 of Tunisian and Spanish, mosquitoes. Consequently, it is difficult to compare the genetic structure of geographically remote populations of $O$. caspius using the same marker. The polymorphism in mtDNA of Italian and Iranian $O$. caspius is 10 times more than that of the ITS2 sequences of Italian, Spanish, and Tunisian O. caspius. O. caspius is thought to have originated in central Asia and later spread to Western Europe and North America (Ross, 1964; Minar, 1976 cited from Milankov et al., 2009). The nucleotide sequence divergence in insect mtDNA is thought to be approximately $2 \%$ for pair-wise divergence per million years (Guillemaud et al., 1997). If so, the differences in COI suggest that it is about one million years since the divergence of the geographically distinct populations in Iran and Italy. During this period, the spread in the distribution of insects was strongly affected by the availability of their habitats, and probably, the distinctions operated at the subspecies level. It would be interesting to compare the DNA of $O$. caspius from Italy and central Asia with other populations of this species using the same set of mitochondrial and nuclear markers.

\section{CONCLUSIONS}

By using molecular analysis it was possible to confirm the presence in the Province of Alessandria of several species of mosquito that are capable of transmitting infections.

The DNA analysis revealed that the Anopheles maculipennis complex in the area of Piedmont includes $A$. messeae, A. maculipennis, A. sacharovi, and A. atroparvus, and the Culex pipiens complex is represented by the antropophilic form molestus. All these species are of high epidemiological significance in Mediterranean countries.

It is suggested that the level of genetic homogeneity in $O$. caspius in the region of Piedmont is high, even though only six individuals were studied. Our data accord with the conclusions reached using other markers such as allozymes and the gene COII, which are not significantly genetically diverse in O. caspius from the plain of the Po River in the north of Italy (Porretta et al., 2004). Probably, there are no genetic barriers preventing crossing between populations of $O$. caspius in northern Italy; this could increase the risk of rapid population growth in this favourable rice field habitat.
A change in the climate in the Piedmont region, together with the development of insecticide resistance, could result in a rapid increase in the abundance and geographic range of mosquito populations. This could complicate the development of an effective control of mosquitoes. The use of a DNA-based method to confirm the identity of mosquito species is likely to greatly reduce the risk of misidentification and results in a more efficient monitoring of control programs.

ACKNOWLEDGEMENTS. The authors are grateful to I. Zakharov and E. Gupalo for comments and advice. We thank N. Oyun for technical help and two anonymous reviewers for their corrections and recommendations. This work was supported by the Russian Foundation for Basic Research (grant 08-0401511-a) and by the Program of Basic Research of the Russian Academy of Sciences "Gene pool and the genetic diversity".

\section{REFERENCES}

Azari-Hamidian S., Yaghoobi-Ershadi M.R., Javadian E., Abai M.R., Mobedi I., Linton Y.M. \& Harbach R.E. 2009: Distribution and ecology of mosquitoes in a focus of dirofilariasis in northwestern Iran, with the first finding of filarial larvae in naturally infected local mosquitoes. Med. Vet. Entomol. 23: 111-121.

BARCODE OF Life InItiative. 2003: http://www.dnabarcodes.org

Becker N., Jost A., Storch V. \& Weitzel T. 1999: Exploiting the biology of urban mosquitoes for their control. In Robinson W.H., Rettich F. \& Rambo G.W. (eds): Proceeding of the $3^{\text {rd }}$ International Conference on Urban Pests. Prague, pp. 425-429.

Becker N., Petric D., Zgomba M., Boase C., Dahl C., Lane J. \& KaIser A. 2003: Mosquitoes and their Control. Kluwer Academic/Plenum Publisher, London, New York, 498 pp.

BOLD Systems http://www.boldsystems.org

Calzolari M., Bonilauri P., Bellini R. et al. 2010: Arboviral survey of mosquitoes in two northern Italian Regions in 2007 and 2008. Vector-Borne Zoonotic Dis. doi:10.1089/vbz.2009. 0176

Ejov M.N., Gordeev M.I., Zvantsov A.B., Goriacheva I.I., Shaikevich E.V. \& Bezzhonova O.V. 2008: Mosquitoes of the Genus Anopheles in Countries of the WHO European Region Having Faced a Recent Resurgence of Malaria. Regional Research Project, 2003-2007. Copenhagen, Denmark, pp. $1-26$.

Fedorova M.V. \& Shaikevich E.V. 2007: Morphological and molecular-genetic differences between the adults of mosquitoes Culex torrentium Martini and Culex pipiens L. from Moscow Province. Entomol. Rev. 87: 127-135.

Folmer O., Black M., Hoeh W., Lutz R. \&, Vrijenhoek R. 1994: DNA primers for amplification of mitochondrial cytochrome c oxidase subunit I diverse metazoan invertebrates. Mol. Marine Biol. Biotechnol. 3: 294-299.

Gad A.M., Farid H.A., Ramzy R.R., Riad M.B., Presley S.M., Cope S.E., Hassan M.M. \& Hassan A.N. 1999: Host feeding of mosquitoes (Diptera: Culicidae) associated with the recurrence of Rift Valley fever in Egypt. J. Med. Entomol. 36: 709-714.

Guillemaud T., Pasteur N. \& Rousset F. 1997: Contrasting levels of variability between cytoplasmic genomes and incompatibility types in the mosquito Culex pipiens. Proc. Soc. Biol. Sci. 22: 245-251.

Marinucci M., Romi R., Mancini P., Di Luca M. \& Severini C. 1999: Phylogenetic relationships of several palearctic mem- 
bers of the maculipennis complex inferred from ITS2 sequence analysis. Insect Mol. Biol. 8: 469-480.

McAbee. R.D., Green E.N., Holeman J., Christiansen J., Frye N., Dealey K., Mulligan III F.S., Brault A.C. \& Cornel A.J. 2008: Identification of Culex pipiens complex mosquitoes in a hybrid zone of west Nile virus transmission in Fresno county, California. Am. J. Trop. Med. Hyg. 78: 303-310.

MetaPathogen: http://www.MetaPathogen.com

Milankov V., Petric D., Vujic A. \& Vapa L. 2009: Taxonomy, biology, genetic variability and medical importance of Ochlerotatus caspius (Pallas, 1771) and O. dorsalis (Meigen, 1830) (Diptera: Culicidae). Acta Entomol. Serb. 14: 195-207.

Nicolescu G., Linton Y.-M., Vladimirescu A., Howard T.M. \& HARBACH R.E. 2004: Mosquitoes of the Anopheles maculipennis group (Diptera: Culicidae) in Romania, with the discovery and formal recognition of a new species based on molecular and morphological evidence. Bull. Entomol. Res. 94: 525-535.

Porretta D., Canestrelli D., Bellini R. \& Urbanelli S. 2007: Improving insect pest management through genetic population data: The case study of the mosquito Ochlerotatus caspius in northern Italy. J. Appl. Ecol. 44: 682-691.
Porter C.H. \& Collins F.H. 1991: Species-diagnostic differences inaribosomal DNA internal transcribed spacer from the sibling species Anopheles freeborni and Anopheles hermsi (Diptera: Culicidae). Am. J. Trop. Med. Hyg. 45: 271-279.

SHAIKEVICH E.V. 2007: PCR-RFLP of the COI gene reliably differentiates C. pipiens, C. pipiens f. molestus and C. torrentium of the Pipiens Complex. Eur. Mosq. Bull. 23: 25-30.

Talbalaghi A.I., Moutailler S., Vazeille M. \& Failloux A.B. 2010: Are Aedes albopictus or other mosquito species from northern Italy competent to sustain new arboviral outbreaks? Med. Veter. Entomol. 24: 83-87.

Tamura K., Dudley J., Nei M. \& Kumar S. 2007: MEGA4: Molecular Evolutionary Genetics Analysis (MEGA) software version 4.0. Mol. Biol. Evol. 24: 1596-1599.

Turell M.J., O'GuinN M.L., Dohm D.J. \& Jones J.W. 2001: Vector competence of North American mosquitoes (Diptera: Culicidae) for West Nile virus. J. Med. Entomol. 38: 130-134.

Vinogradova E.B., Shaikevich E.V. \& Ivanitsky A.V. 2007: The study on the distribution of the Culex pipiens complex mosquitoes in the European part of Russia by molecular methods of their identification. Compar. Cytogen. 1: 129-138.

Received June 8, 2010; revised and accepted July 28, 2010 